\title{
Validation of machine learning models to predict dementia-related neuropsychiatric symptoms in real-world data
}

\section{Javier Mar ( $\sim$ JAVIER.MARMEDINA@osakidetza.eus )}

Hospital Alto Deba https://orcid.org/0000-0002-9455-4869

\section{Ania Gorostiza}

Hospital Alto Deba

\section{Oliver Ibarrondo}

Hospital Alto Deba

\section{Carlos Cernuda}

Mondragon Unibertsitatea Escuela Politecnica Superior

\section{Arantzazu Arrospide}

Hospital Alto Deba

\section{Álvaro Iruin}

Osakidetza-Servicio Vasco de Salud

Igor Larrañaga

Hospital Alto Deba

Mikel Tainta

Hospital de Zumarraga

\section{Enaitz Ezpeleta}

Mondragon Unibertsitatea Escuela Politecnica Superior

Ane Alberdi

Mondragon Unibertsitatea Escuela Politecnica Superior

\section{Research}

Keywords: Neuropsychiatric symptoms, dementia, psychotic symptoms, depressive symptoms, machine learning, real-world data, prevalence, predictive model

Posted Date: March 20th, 2020

DOI: https://doi.org/10.21203/rs.3.rs-17985/v1

License: (c) (i) This work is licensed under a Creative Commons Attribution 4.0 International License.

Read Full License 


\section{Abstract}

Background Neuropsychiatric symptoms (NPS) are the leading cause of the social burden of dementia but their role is underestimated. The objective of the study was to validate predictive models to separately identify psychotic and depressive symptoms in patients diagnosed with dementia using clinical databases representing the whole population (real-world data).

Methods First, we searched the electronic health records of 4,003 patients with dementia to identify NPS. Second, machine learning (random forest) algorithms were applied to build in the training sample $(\mathrm{N}=3,003)$ separate predictive models for psychotic and depressive symptoms. In order to evaluate the classification ability of the models, the following statistics were calculated for each model: the area under the receiver operating curve (AUC), sensitivity, specificity, accuracy, no-information rate and Kappa index. Third, calibration and discrimination were assessed in the validation sample $(N=1,000)$ to assess the performance of the models. A calibration curve was drawn by plotting the predicted probabilities for groups on the $x$-axis and the mean observed values on the $y$-axis.

Results Neuropsychiatric symptoms were noted in the electronic health record of $58 \%$ of patients. The AUC reached 0.80 for the psychotic symptoms model and 0.74 for the depressive symptoms model. The Kappa index and accuracy also showed better discrimination in the psychotic model. Calibration plots indicated that both types of model had less predictive accuracy when the probability of neuropsychiatric symptoms was $<25 \%$. The most important variables in the psychotic symptom model were use of risperidone, level of sedation, quetiapine and haloperidol and the number of antipsychotics prescribed. In the depressive symptom model, the most important variable was number of antidepressants prescribed, use of escitalopram, level of sedation and age.

Conclusions More than half of the sample had NPS as identified by the presence of key terms in the electronic health record. Although NPS are not encoded, they are treated with antipsychotics and antidepressants, which allows developing valid predictive models by joining machine learning tools and real-world data. Given their good performance, the predictive models can be used to estimate prevalence of NPS in population databases.

\section{Introduction}

Neuropsychiatric symptoms (NPS) are the leading cause of the social burden of dementia as they constitute the key factor in families' giving up on keeping patients at home [1, 2]. It could be thought that they are well acknowledged as $8 \%$ of new drugs currently under evaluation for Alzheimer's disease are intended to treat NPS [3]. On the other hand, their population impact is underestimated as they are not well coded in health records [4-6], this implying inadequate clinical management [7]. In order to break the vicious circle established by the underestimation of the impact and the lack of proper recording of these symptoms, there is a need for tools providing information to monitor intervention plans from a population perspective $[1,8,9]$. 
The prevalence of NPS has been measured in clinical samples using questionnaires such as the Neuropsychiatric Inventory (NPI) that are rarely applied in clinical practice $[4,10]$, and the prevalence found varies depending on whether the cases are identified in the community or nursing homes.

Specifically, NPS are less common (56-98\%) and less severe in individuals with dementia living in the community than in those in hospitals or long-term care facilities (91-96\%) $[1,11]$. The problem with these figures is that they cannot be extrapolated to populations as a whole due to their heterogeneous distribution of dementia stages [9]. This distribution could be measured by analyzing a random sample of the general population using a door-to-door survey [4]. Notably, however, another study design is now feasible based on anonymized databases built from electronic health records (EHRs). This approach based on real-world data (RWD) has already been used to validate the diagnosis of dementia $[12,13]$ and the presence of agitation [6] but not to explore rates of NPS. On the other hand, validation studies are required in order to systematically use RWD as a source of epidemiological information $[7,14]$. RWD have been described in an Organisation for Economic Co-operation and Development report as "broad data" because they cover large populations but include limited amounts of outcome and exposure data [15]. In line with this, machine learning $(\mathrm{ML})$ tools have been postulated as having more capacity to predict complex clinical conditions like NPS [15] and being able to convert RWD into "smart data" $[15,16]$. An example of this would be the calculation of the prevalence of NPS in population samples. While this design has been previously applied in cardiovascular research [17] and Alzheimer's disease neuroimaging [18], no examples have been reported of its use to measure features of dementia-related NPS at population level [19]. Therefore, the objective of this study was to construct and validate predictive models based on ML tools to identify the presence of psychotic and/or depressive symptoms in dementia-diagnosed patients from administrative and clinical databases that cover entire populations.

\section{Methods}

Design

We carried out a retrospective cross-sectional study to evaluate the validity of the EHR to identify dementia-related NPS. Data were obtained from a population registry of dementia cases built using the Basque Health Service's institutional database, Oracle Business Intelligence (OBI), containing administrative and clinical records for primary, inpatient, emergency and outpatient care in an anonymized form which are updated daily $[4,12]$. The study protocol was approved by the Clinical Research Ethics Committee (CEIC) of the Basque Country (registration number PI2018143 EPA-OD).

The registry included all patients diagnosed with dementia in $\mathrm{OBI}$ but our target population consisted only of individuals alive on 31 December $2018(n=31,000)$. The validation of the diagnosis of dementia in this registry evidenced adequate predictive values (positive and negative predictive values of $95.1 \%$ and 99.4\% respectively) [12]. Criteria used for the diagnosis of dementia are described in the supplementary material. As previously noted, NPS are poorly coded but they are recorded as text in the EHR [4]. Given the full deployment of electronic prescriptions from 2008, medication prescribing is highly accurately recorded in OBI. Our hypothesis was that drug prescriptions together with other clinical variables could be 
used to build a predictive model to identify dementia-related BPS in our institutional database. Therefore, we carried out a validation study classifying NPS into two patterns characterized, on the one hand, by depressive or mood disorders, and on the other, by behavioral or psychotic disorders [4]. The dataset used and analyzed during the current study is available from the corresponding author on reasonable request.

\section{Validation study}

In a random sample of patients with dementia, the EHRs were individually reviewed by a trained clinical coding technician, supervised by a psychiatrist, looking within physicians' notes for evidence of the presence of the two types of symptoms. The technician was blinded to the OBI diagnostic codes. Within NPS, we differentiated between mood disorders (depression, anxiety and apathy) and psychotic disorders (aggressiveness, irritability, restlessness and shouts of visual, auditory and delirious hallucinations). The terms mood disorders, apathy, bradypsychia, psychomotor slowness, sadness, depression, anxiety and negativism were sought as markers of depressive symptoms or mood disorders, and psychotic symptoms, behavioral symptoms, agitation, irritability, aggressiveness, restlessness, screams, visual or auditory hallucinations, delusions, alterations of behavior, erratic wandering, escape attempts, disinhibition and rejection of care as markers of psychotic or behavioral symptoms.

Variables

The EHR review supplied data on the two response variables used in the predictive models, namely, the presence of mood and/or behavioral symptoms. Regarding the explanatory variables, the following were considered: age, sex, institutionalization status, concomitant diagnoses (diabetes mellitus, hypertension, dyslipidemia, thyroid disease, Parkinson's disease, stroke, cardiovascular disease, head trauma, depressive disorder and psychotic disorder) and pharmacological treatment. We collected data on all prescriptions of medications in the following specific Anatomical Therapeutic Chemical Classification System subgroups: N06D (donepezil, rivastigmine and galantamine and Memantine), N06A (antidepressants), N05A and N06C (antipsychotics), NO5B (anxiolytic) and N05C (hypnotics). As the hypothesis that the prescribing of antidepressants and antipsychotics can be used to detect NPS in population databases was the rationale for the current study, all the prescriptions and changes in prescriptions involving the aforementioned subgroups were recorded. This data collection process resulted in a longitudinal dataset with $\mathrm{n}$ data instances per participant, $\mathrm{n}$ being the number of different drug prescriptions issued to them over time. This longitudinal information was then used to create new summarizing variables to obtain a single data instance per participant. These summarizing variables included baseline features, concomitant diagnoses over time, sedative effects (highest level of sedation ever prescribed to the patient), drug prescriptions and changes therein (number of antidepressants prescribed, number of antipsychotics prescribed, number of changes from antidepressants to antipsychotics and number of changes from antipsychotics to antidepressants) and the two response variables (NPS documented in the EHR notes) (Table S1 in the Supplementary material). The level of sedation produced by each drug was categorized (0: none; 1 : minimum; 2: mild; 3 : moderate; 4 : deep) as set out in Table S2 in the Supplementary Material. 
All the preprocessing of the dataset and predictive modelling was done in $\mathrm{R}$.

Machine learning

The sample $(\mathrm{N})$ was randomly divided into a training set $\left(\mathrm{N}_{1}=0.75 * \mathrm{~N}\right)$ and a validation set $\left(\mathrm{N}_{2}=0.25\right.$ * $\mathrm{N})$. It was checked that patient characteristics did not differ between training and validation sets. The ML random forest approach, fully described in the Supplementary Material, was applied to build predictive models [20]. The random forest algorithm [21] is a stochastic ensemble method that uses bagging, a combination of bootstrapping and aggregation of weak learners, more specifically, decision trees, seeking to detect patterns in data and use these to predict outcomes, in our case, NPS [19].

In the training set, we followed a stepwise process beginning with baseline models whose performance was improved by adding other explanatory variables in an iterative way to test their contribution. Mean decrease accuracy was used to assess the relative feature importance of the variables in the models [22]. This technique computes the accuracy of the trees that build the model for the out-of-the bag sample of each tree. Then, for each variable, it permutes the values of the variables one after another and measures how much the accuracy changes. Any decrease in accuracy resulting from this permutation is averaged over all trees, and used as a measure of the importance of each variable in the random forest model.

All the predictive models have been evaluated using a k-fold cross validation approach, with $k=10$ and 10 repetitions. The main advantage of this evaluation technique is that it maximizes the availability of data for training the models, as it allows all the data instances to be used both for training and validation purposes in different iterations. In addition, it gives accurate estimates of the performance of the prediction models for unseen data. The same process was carried out separately for the psychotic and depressive symptom models for which discriminatory power was assessed.

Discriminatory power refers to the ability of a prediction model to distinguish between two outcome classes. In order to evaluate the classification ability of the models, the following statistics were calculated for each model: the area under the receiver operating curve (AUC), sensitivity, specificity, accuracy, no-information rate and Kappa index. The AUC gives an overview of a model's ability to discriminate between positive and negative classes, independently of their prevalence, and is therefore suitable for imbalanced datasets. Sensitivity or the true positive rate is defined as the number of cases from the positive class that were predicted correctly by the model, while specificity or the true negative rate refers to the number of cases from the negative class that were actually predicted as negative. The no-information rate is the accuracy that can be achieved without a model, and for a model, accuracy means the percentage of correct classifications it provides. The Kappa index measures the agreement between two approaches to classify mutually exclusive categories, agreement being characterized as slight (for values of $0-0.20)$, fair $(0.21-0.40)$, moderate $(0.41-0.60)$ or substantial $(0.61-0.80)$ [23].

Evaluation of model performance in the validation dataset 
Model performance was measured by assessing both calibration and discrimination in the validation set [24-26]. Calibration is related to goodness-of-fit, which reflects the agreement between observed outcomes and predictions. To assess this, a calibration curve was drawn by plotting the predicted probabilities for groups on the $x$-axis and the mean observed values on the $y$-axis. Finally, discriminatory power was assessed with the same statistics as in the training stage.

\section{Results}

The resulting dataset contained 62 variables and 4,003 cases, the main features of which are described in Table 1. Psychotic symptoms were documented in the EHR of $58 \%$ of the population and depressive or mood disorder in 59\%. The dataset was randomly divided into a training set $(\mathrm{N} 1=3003)$ and a validation set $(\mathrm{N} 2=1000)$. These types of symptoms were more common in men than in women. The pattern with age was different: the group with psychotic disorders being older in age and those with depressive disorder younger. Living in a nursing home was strongly associated with both types of symptoms. Table S3 summarizes the pharmacological treatments based on data from the EHR review by type of disorder, while Table S4 compares patient characteristics in training and validation sets. 
Table 1

Characteristics of patients disaggregated by psychotic and depressive disorder based on health record review.

\begin{tabular}{|c|c|c|c|c|c|c|}
\hline & \multicolumn{2}{|c|}{$\begin{array}{l}\text { Psychotic symptoms } \\
\text { in EHR }\end{array}$} & \multicolumn{4}{|c|}{$\begin{array}{l}\text { Depressive } \\
\text { symptoms in EHR }\end{array}$} \\
\hline & $\begin{array}{l}\text { Yes } \\
N= \\
2,307\end{array}$ & $\begin{array}{l}\text { No } \\
N=1,696\end{array}$ & $\begin{array}{l}\text { Yes } \\
N=2,356\end{array}$ & $\begin{array}{l}\text { No } \\
N= \\
1,647\end{array}$ & $\begin{array}{l}\text { Total } \\
N= \\
4,003\end{array}$ & $\mathrm{~N}$ \\
\hline Sex: female & $\begin{array}{l}1,572 \\
(68.1 \%)\end{array}$ & $\begin{array}{l}1,230 \\
\text { (72.5\%) }\end{array}$ & $\begin{array}{l}1,717 \\
(72.9 \%)\end{array}$ & $\begin{array}{l}1,085 \\
(65.9 \%)\end{array}$ & $\begin{array}{l}2,802 \\
(70.0 \%)\end{array}$ & 4,003 \\
\hline Age $^{\star}$ & $\begin{array}{l}86 \\
{[81 ; 90]}\end{array}$ & $85[79 ; 89]$ & $84[79 ; 89]$ & $\begin{array}{l}87 \\
{[82 ; 90]}\end{array}$ & $\begin{array}{l}85 \\
{[80 ; 89]}\end{array}$ & 4,003 \\
\hline Nursing home & $\begin{array}{l}697 \\
(30.2 \%)\end{array}$ & $\begin{array}{l}246 \\
(14.5 \%)\end{array}$ & $\begin{array}{l}576 \\
(24.4 \%)\end{array}$ & $\begin{array}{l}367 \\
(22.3 \%)\end{array}$ & $\begin{array}{l}943 \\
(23.6 \%)\end{array}$ & 4,003 \\
\hline Hypertension & $\begin{array}{l}1,392 \\
(60.3 \%)\end{array}$ & $\begin{array}{l}1,006 \\
(59.3 \%)\end{array}$ & $\begin{array}{l}1,413 \\
(60.0 \%)\end{array}$ & $\begin{array}{l}985 \\
(59.8 \%)\end{array}$ & $\begin{array}{l}2398 \\
(59.9 \%)\end{array}$ & 4,003 \\
\hline Diabetes mellitus & $\begin{array}{l}616 \\
(26.7 \%)\end{array}$ & $\begin{array}{l}428 \\
(25.2 \%)\end{array}$ & $\begin{array}{l}584 \\
(24.8 \%)\end{array}$ & $\begin{array}{l}460 \\
(27.9 \%)\end{array}$ & $\begin{array}{l}1044 \\
(26.1 \%)\end{array}$ & 4,003 \\
\hline Dyslipidemia & $\begin{array}{l}1,173 \\
(50.8 \%)\end{array}$ & $\begin{array}{l}886 \\
(52.2 \%)\end{array}$ & $\begin{array}{l}1,282 \\
(54.4 \%)\end{array}$ & $\begin{array}{l}777 \\
(47.2 \%)\end{array}$ & $\begin{array}{l}2059 \\
(51.4 \%)\end{array}$ & 4,003 \\
\hline Thyroid disease & $\begin{array}{l}433 \\
(18.8 \%)\end{array}$ & $\begin{array}{l}331 \\
(19.5 \%)\end{array}$ & $\begin{array}{l}472 \\
(20.0 \%)\end{array}$ & $\begin{array}{l}292 \\
(17.7 \%)\end{array}$ & $\begin{array}{l}764 \\
(19.1 \%)\end{array}$ & 4,003 \\
\hline Parkinson's disease & $\begin{array}{l}146 \\
(6.33 \%)\end{array}$ & $\begin{array}{l}47 \\
(2.77 \%)\end{array}$ & $\begin{array}{l}141 \\
(5.98 \%)\end{array}$ & $\begin{array}{l}52 \\
(3.16 \%)\end{array}$ & $\begin{array}{l}193 \\
(4.82 \%)\end{array}$ & 4,003 \\
\hline Stroke & $\begin{array}{l}724 \\
(31.4 \%)\end{array}$ & $\begin{array}{l}488 \\
(28.8 \%)\end{array}$ & $\begin{array}{l}705 \\
(29.9 \%)\end{array}$ & $\begin{array}{l}507 \\
(30.8 \%)\end{array}$ & $\begin{array}{l}1212 \\
(30.3 \%)\end{array}$ & 4,003 \\
\hline Cardiovascular disease & $\begin{array}{l}478 \\
(20.7 \%)\end{array}$ & $\begin{array}{l}312 \\
(18.4 \%)\end{array}$ & $\begin{array}{l}453 \\
(19.2 \%)\end{array}$ & $\begin{array}{l}337 \\
(20.5 \%)\end{array}$ & $\begin{array}{l}790 \\
(19.7 \%)\end{array}$ & 4,003 \\
\hline Traumatic brain injury & $\begin{array}{l}426 \\
(18.5 \%)\end{array}$ & $\begin{array}{l}230 \\
(13.6 \%)\end{array}$ & $\begin{array}{l}385 \\
(16.3 \%)\end{array}$ & $\begin{array}{l}271 \\
(16.5 \%)\end{array}$ & $\begin{array}{l}656 \\
(16.4 \%)\end{array}$ & 4,003 \\
\hline Antipsychotic treatment & $\begin{array}{l}1,628 \\
(70.6 \%)\end{array}$ & $\begin{array}{l}467 \\
(27.5 \%)\end{array}$ & $\begin{array}{l}1,337 \\
(56.7 \%)\end{array}$ & $\begin{array}{l}758 \\
(46.0 \%)\end{array}$ & $\begin{array}{l}2095 \\
(52.3 \%)\end{array}$ & 4,003 \\
\hline No. of antipsychotics prescribed & $1[1 ; 2]$ & $1[1 ; 1]$ & $1[1 ; 2]$ & $1[1 ; 2]$ & $1[1 ; 2]$ & 2,095 \\
\hline $\begin{array}{l}\text { Changes from antipsychotic to } \\
\text { antidepressant }\end{array}$ & & & & & & 2,095 \\
\hline No changes & $\begin{array}{l}256 \\
(15.7 \%)\end{array}$ & $\begin{array}{l}114 \\
(24.4 \%)\end{array}$ & $\begin{array}{l}165 \\
(12.3 \%)\end{array}$ & $\begin{array}{l}205 \\
(27.0 \%)\end{array}$ & $\begin{array}{l}370 \\
(17.7 \%)\end{array}$ & \\
\hline
\end{tabular}

*Median [interquartile range]; EHR: electronic health record 


\begin{tabular}{|c|c|c|c|c|c|c|}
\hline \multirow[b]{2}{*}{$\geq 1$ change } & \multicolumn{2}{|c|}{$\begin{array}{l}\text { Psychotic symptoms } \\
\text { in EHR }\end{array}$} & \multicolumn{4}{|c|}{$\begin{array}{l}\text { Depressive } \\
\text { symptoms in EHR }\end{array}$} \\
\hline & $\begin{array}{l}1,372 \\
(84.3 \%)\end{array}$ & $\begin{array}{l}353 \\
(75.6 \%)\end{array}$ & $\begin{array}{l}1,172 \\
(87.7 \%)\end{array}$ & $\begin{array}{l}553 \\
(73.0 \%)\end{array}$ & $\begin{array}{l}1,725 \\
(82.3 \%)\end{array}$ & \\
\hline $\begin{array}{l}\text { No. of changes from } \\
\text { antipsychotic to antidepressant }\end{array}$ & $1[1 ; 2]$ & $1[1 ; 1]$ & $1[1 ; 2]$ & $1[1 ; 1]$ & $1[1 ; 1]$ & 1,725 \\
\hline Antidepressant treatment & $\begin{array}{l}1,731 \\
(75.0 \%)\end{array}$ & $\begin{array}{l}988 \\
(58.3 \%)\end{array}$ & $\begin{array}{l}1890 \\
(80.2 \%)\end{array}$ & $\begin{array}{l}829 \\
(50.3 \%)\end{array}$ & $\begin{array}{l}2719 \\
(67.9 \%)\end{array}$ & 4,003 \\
\hline $\begin{array}{l}\text { No. of antidepressants } \\
\text { prescribed }\end{array}$ & $1[1 ; 2]$ & $1[1 ; 2]$ & $2[1 ; 2]$ & $1[1 ; 2]$ & $1[1 ; 2]$ & 2,719 \\
\hline $\begin{array}{l}\text { Changes from antidepressant to } \\
\text { antipsychotic: }\end{array}$ & & & & & & 2,719 \\
\hline No changes & $\begin{array}{l}699 \\
(40.4 \%)\end{array}$ & $\begin{array}{l}764 \\
(77.3 \%)\end{array}$ & $\begin{array}{l}958 \\
(50.7 \%)\end{array}$ & $\begin{array}{l}505 \\
(60.9 \%)\end{array}$ & $\begin{array}{l}1,463 \\
(53.8 \%)\end{array}$ & \\
\hline$\geq 1$ change & $\begin{array}{l}1,032 \\
(59.6 \%)\end{array}$ & $\begin{array}{l}224 \\
(22.7 \%)\end{array}$ & $\begin{array}{l}932 \\
(49.3 \%)\end{array}$ & $\begin{array}{l}324 \\
(39.1 \%)\end{array}$ & $\begin{array}{l}1,256 \\
(46.2 \%)\end{array}$ & \\
\hline $\begin{array}{l}\text { No. of changes from } \\
\text { antidepressant to antipsychotic }\end{array}$ & $1[1 ; 2]$ & $1[1 ; 1]$ & $1[1 ; 2]$ & $1[1 ; 1]$ & $1[1 ; 1]$ & 1,256 \\
\hline Level of sedation: & & & & & & 4,003 \\
\hline None & $\begin{array}{l}383 \\
(16.6 \%)\end{array}$ & $\begin{array}{l}843 \\
(49.7 \%)\end{array}$ & $\begin{array}{l}579 \\
(24.6 \%)\end{array}$ & $\begin{array}{l}647 \\
(39.3 \%)\end{array}$ & $\begin{array}{l}1,226 \\
(30.6 \%)\end{array}$ & \\
\hline Minimal & $\begin{array}{l}55 \\
(2.38 \%)\end{array}$ & $\begin{array}{l}160 \\
(9.43 \%)\end{array}$ & $\begin{array}{l}109 \\
(4.63 \%)\end{array}$ & $\begin{array}{l}106 \\
(6.44 \%)\end{array}$ & $\begin{array}{l}215 \\
(5.37 \%)\end{array}$ & \\
\hline Mild & $\begin{array}{l}761 \\
(33.0 \%)\end{array}$ & $\begin{array}{l}570 \\
(33.6 \%)\end{array}$ & $\begin{array}{l}842 \\
(35.7 \%)\end{array}$ & $\begin{array}{l}489 \\
(29.7 \%)\end{array}$ & $\begin{array}{l}1,331 \\
(33.3 \%)\end{array}$ & \\
\hline Moderate & $\begin{array}{l}1,088 \\
(47.2 \%)\end{array}$ & $\begin{array}{l}121 \\
(7.13 \%)\end{array}$ & $\begin{array}{l}809 \\
(34.3 \%)\end{array}$ & $\begin{array}{l}400 \\
(24.3 \%)\end{array}$ & $\begin{array}{l}1,209 \\
(30.2 \%)\end{array}$ & \\
\hline Deep & $\begin{array}{l}20 \\
(0.87 \%)\end{array}$ & $\begin{array}{l}2 \\
(0.12 \%)\end{array}$ & $\begin{array}{l}17 \\
(0.72 \%)\end{array}$ & $\begin{array}{l}5 \\
(0.30 \%)\end{array}$ & $\begin{array}{l}22 \\
(0.55 \%)\end{array}$ & \\
\hline
\end{tabular}

Table 2 shows the performance of the models tested for psychotic and depressive symptoms in both training and validation sets. The iterations and modelling variables tested in each model are also summarized in Table 2. The analysis of the raw data without other variables indicates that antipsychotic prescribing is more specific and antidepressant prescribing more sensitive for identifying NPS. Notably, the models seeking to predict psychotic symptoms perform better, reaching an AUC of 0.80 , than the depressive symptom models (maximum AUC of 0.74). Other statistics like the kappa index and accuracy also evidenced that the psychotic symptom models had better discriminatory power. 
Table 2

Performance of models for psychotic symptoms and depressive symptoms in the training and validation datasets.

\begin{tabular}{|c|c|c|c|c|c|c|c|}
\hline $\begin{array}{l}\text { Model for psychotic } \\
\text { symptoms }\end{array}$ & $N(v)$ & AUC (Cl) & Sens. & Spec. & Accuracy & $\begin{array}{l}\text { No- } \\
\text { info. } \\
\text { rate }\end{array}$ & Kappa \\
\hline $\begin{array}{l}\text { Base case ( } \geq 1 \text { antipsychotic } \\
\text { prescribed) }\end{array}$ & 1 & & 0.706 & 0.725 & & & \\
\hline \multicolumn{8}{|l|}{ Training set } \\
\hline $\begin{array}{l}\text { 1: antipsychotics + } \\
\text { antidepressants }\end{array}$ & 2 & $\begin{array}{l}0.741 \\
(0.711- \\
0.741)\end{array}$ & 0.712 & 0.722 & 0.716 & 0.587 & 0.425 \\
\hline $\begin{array}{l}\text { 2: specific antipsychotics + } \\
\text { specific antidepressants }\end{array}$ & 21 & $\begin{array}{l}0.802 \\
(0.775- \\
0.802)\end{array}$ & 0.653 & 0.857 & 0.737 & 0.587 & 0.485 \\
\hline $\begin{array}{l}3: 2+\text { changes in } \\
\text { prescriptions }\end{array}$ & 23 & $\begin{array}{l}0.797 \\
(0.77- \\
0.797)\end{array}$ & 0.660 & 0.848 & 0.737 & 0.587 & 0.484 \\
\hline $\begin{array}{l}\text { 4: } 3+\text { age }+ \text { sex }+ \text { sedation }+ \\
\text { comorbidities }+ \text { nursing home }\end{array}$ & 35 & $\begin{array}{l}0.807 \\
(0.781- \\
0.807)\end{array}$ & 0.692 & 0.802 & 0.737 & 0.587 & 0.477 \\
\hline \multicolumn{8}{|l|}{ Validation set } \\
\hline $\begin{array}{l}\text { 4: model for psychotic } \\
\text { symptoms }\end{array}$ & 35 & $\begin{array}{l}0.807 \\
(0.780- \\
0.807)\end{array}$ & 0.693 & 0.806 & 0.740 & 0.587 & 0.482 \\
\hline $\begin{array}{l}\text { Model for depressive } \\
\text { symptoms }\end{array}$ & $N(v)$ & AUC (Cl) & Sens. & Spec. & Accuracy & $\begin{array}{l}\text { No- } \\
\text { info. } \\
\text { rate }\end{array}$ & Kappa \\
\hline $\begin{array}{l}\text { Base case ( } \geq 1 \\
\text { antidepressant prescribed) }\end{array}$ & 1 & & 0.802 & 0.497 & & & \\
\hline \multicolumn{8}{|l|}{ Training set } \\
\hline $\begin{array}{l}\text { 1: antipsychotics + } \\
\text { antidepressants }\end{array}$ & 2 & $\begin{array}{l}0.665 \\
(0.633- \\
0.665)\end{array}$ & 0.823 & 0.495 & 0.693 & 0.604 & 0.331 \\
\hline
\end{tabular}

$\mathrm{N}(\mathrm{v})$ : number of variables; AUC: area under the receiver operating curve; Sens.: sensitivity; Spec.: specificity.

AUC: Area under the curve

AUC: Area under the curve 


\begin{tabular}{|c|c|c|c|c|c|c|c|}
\hline $\begin{array}{l}\text { Model for psychotic } \\
\text { symptoms }\end{array}$ & $N(v)$ & $\operatorname{AUC}(\mathrm{Cl})$ & Sens. & Spec. & Accuracy & $\begin{array}{l}\text { No- } \\
\text { info. } \\
\text { rate }\end{array}$ & Kappa \\
\hline $\begin{array}{l}\text { 2: specific antipsychotics + } \\
\text { specific antidepressants }\end{array}$ & 21 & $\begin{array}{l}0.719 \\
(0.687- \\
0.719)\end{array}$ & 0.707 & 0.659 & 0.688 & 0.604 & 0.359 \\
\hline $\begin{array}{l}\text { 3: } 2+\text { changes in } \\
\text { prescriptions }\end{array}$ & 23 & $\begin{array}{l}0.715 \\
(0.682- \\
0.715)\end{array}$ & 0.699 & 0.683 & 0.693 & 0.604 & 0.373 \\
\hline $\begin{array}{l}\text { 4: } 3+\text { age }+ \text { sex }+ \text { sedation }+ \\
\text { comorbidities }+ \text { nursing home }\end{array}$ & 35 & $\begin{array}{l}0.739 \\
(0.708- \\
0.739)\end{array}$ & 0.759 & 0.627 & 0.706 & 0.604 & 0.386 \\
\hline \multicolumn{8}{|l|}{ Validation set } \\
\hline $\begin{array}{l}\text { 4: model for depressive } \\
\text { symptoms }\end{array}$ & 35 & $\begin{array}{l}0.74 \\
(0.709- \\
0.74)\end{array}$ & 0.75 & 0.629 & 0.702 & 0.604 & 0.378 \\
\hline \multicolumn{8}{|c|}{$\begin{array}{l}\mathrm{N}(\mathrm{v}) \text { : number of variables; AUC: area under the receiver operating curve; Sens.: sensitivity; Spec.: } \\
\text { specificity. }\end{array}$} \\
\hline \multicolumn{8}{|l|}{ AUC: Area under the curve } \\
\hline AUC: Area under the curve & & & & & & & \\
\hline
\end{tabular}

Figure 1 and Table S5 indicate the importance of variables in the selected models. The most important ones in the psychotic symptom model are use of risperidone and level of sedation achieved by all the drugs prescribed, followed by use of quetiapine and haloperidol and the number of antipsychotics prescribed. Other important variables were the prescribing of trazodone, and sulpiride and number of changes from antidepressants to antipsychotics. In the depressive symptom model, the most important variable is number of antidepressants prescribed followed by use of escitalopram, level of sedation and age. In this model, other important variables were the prescribing of sertraline, duloxetine, mirtazapine, citalopram and the number of changes from antipsychotics to antidepressants.

Figure 2 shows the calibration plot for the validation dataset. If the model calibration were to be perfect, the points should lie on or around the $45^{\circ}$ line of the plot. In our case, the models had poorer predictive power when the probability of NPS was lower than 0.25. Finally, Fig. 3 included in the supplementary material shows the ROC curves obtained in the validation dataset for each of the models. As measured with the AUC (Table 2 and Fig. 3), the curves demonstrate graphically the better predictive ability of the psychotic symptom model.

\section{Discussion}


To our knowledge, this is the first time that $\mathrm{ML}$ techniques have been applied to build and validate models based on real-world population data to estimate the prevalence of NPS in dementia. This study shows that ML-based models are good at predicting dementia-related NPS and opens the prospect of applying these techniques in population databases. The raw results showed that more than half of the sample had NPS as identified by the presence of key terms in the EHR. This fits well with the findings of Halpern et al. who found evidence of agitation in $44.6 \%$ of all patients when analyzing the EHR notes of dementia patients [6].

Considering AUCs of $0.70-0.79$ to indicate acceptable and $\geq 0.80$ excellent discrimination, the psychotic symptom model can be classified as excellent and the depressive symptom model as acceptable [27]. Given these classifications, it would be valid to apply the results to the whole population database. They are consistent with the expected higher specificity of models for psychosis. When data collected from EHRs are applied to research, avoiding false-positive diagnoses may be more important than avoiding false negatives. In longitudinal studies, for example, false positives can dilute observed effects and reduce statistical power [28]. Therefore, our approach is valid for epidemiological research on dementiarelated NPS. Consistent with the AUC values, other statistics used, namely accuracy and the kappa index, also indicated that the model predicting psychotic symptoms performed better.

As previously mentioned, however, the calibration was poor when the probability of NPS estimated by the model was low. This implies that both models systematically underestimated disease rates observed in the EHR. The explanation for this may be that when the symptoms are of recent onset the recording of symptoms in the EHR is not yet accompanied by pharmacological treatment. Nonetheless, in more advanced stages of the disease, clinicians treat such symptoms, and hence, the calibration line overlaps the $45^{\circ}$ line of the plot. The models' calibration is excellent for these late stages, observed and predicted cases fitting well.

Our framework for analyzing the NPS was based on the differentiation in individual clinical symptoms between two broad categories or constructs, because analyzing individual symptoms would lead to overly complex analysis. In 2015, the International Psychogeriatric Association developed a provisional consensus definition of agitation [29]. Currently, this association is updating the criteria for psychosis in Major and Mild Neurocognitive Disorder and has described agitation and depression specifically as associated features for NPS. The different level of importance of the variables in the two models corroborates the usefulness of the two-category classification usefulness. Nonetheless, there is agreement on the importance of the changes in medication and their sedative properties. As in the Chinese metaphor about cats, perhaps it does not matter whether a drug is an antidepressant or an antipsychotic so long as it produces sedation. Instead of being avoided as an adverse effect of treatment [30], it seems that sedation is the mechanism sought to reduce agitation. The other key associated variable is patients changing from one prescription to another (antidepressant to antipsychotic or vice versa). Day-to-day fluctuations in clinical symptoms are interpreted as treatment failure which boosts the recording of symptoms in the EHR and leads to the use of new drugs. 
The plot showing the importance of variables for psychotic disorder highlights the role of risperidone and quetiapine in its pharmacological treatment. It was to be expected that risperidone would be the drug that contributed the most predictive value to the psychotic symptom model because it is the only one for which this indication is included in its summary of product characteristics. The great gap between recommendations and reality is evidenced by the role of quetiapine, which is the second most important medication even though its indication for dementia is off label. On the other hand, the level of sedation achieved by the medications used also had a high explanatory capacity, and medication changes contributed considerably to the predictive value of the psychotic symptom model. NPS affect almost all individuals with dementia (97\%) over the course of the disease [3], and although they fluctuate [4], they rarely disappear, and this makes level of sedation particularly important. Families seldom have access to specialized clinics to deal with such fluctuations and family caregivers often manage them by adjusting doses by trial and error. If that does not work, families turn to the most accessible doctor to change the drug prescribed because they cannot cope with the stress. This explains the high importance in the model of the variables indicating the number of antipsychotic treatments and changes from antidepressant to antipsychotic drugs. Notably, antidepressant drugs also play a relevant role in the psychotic symptom model. Not only trazodone but also sertraline, mirtazapine and paroxetine were important in the rating classification. The most important antidepressants in the model addressing psychotic symptoms were mirtazapine and trazodone, which are most likely used for their sedative effect. In contrast, the prescribing of sertraline and paroxetine could have more to do with their antidepressant effects and ease of use due to fewer side effects. We believe that their role reflects a history of both psychotic and mood disorders in some cases. A few non-pharmacological variables showed importance, namely, comorbidities (Parkinson's disease and stroke) and living in a nursing home. Nonetheless, their explanatory power was very weak compared with that of pharmacological variables.

The model predicting depressive symptoms was based on different variables, the most important one being the number of antidepressants prescribed. Escitalopram is the first individual drug in the ranking, and is followed by level of sedation and age. This model seemed to be more homogeneous as it relied much less on antipsychotic drugs and comorbidities. Moreover, living in a nursing home played a trivial role. Despite this homogeneity, its predictive power was much lower, especially because of the lower specificity. The model identified positive cases well, but failed to rule out negative ones.

Various authors have underlined the need to integrate evidence from heterogeneous sources including clinical trials, cohort data and RWD to evaluate disease progression and build health economic models for dementia treatment $[15,31,32]$. Nonetheless, RWD lack consistency in the collection of outcomes and monitoring of disease severity. In this scenario, validation of variables available from EHRs appears as a key first step towards an $A D /$ dementia integrated curated data environment fed from multiple sources [15]. Brayne et al. pointed out the crucial importance of approaches to dementia research being anchored in the true population as selective participation in observational studies may systematically bias findings [33]. 
Our work is not without limitations and the main one is that no validated scale such as the NPI was used to identify the presence of NPS in patients with dementia [10]. Finding specific terms in an EHR review only reveals that a physician recorded symptoms linked to the presence of behavior and depressive disorders. The identification of dementia cases could also be deemed problematic, as some authors have questioned the use of Medicare claims to identify dementia [34]. On the other hand, the aim of such claims is to allow physicians to be paid. In contrast, our database is obtained directly from a unified EHR used by all healthcare professionals (physicians and nurses) to document all patients' contacts with the health service in all care settings (primary, emergency, inpatient, home and outpatient care). The system includes an automatic coding system (ICD-10) managed by physicians when they provide care to patients. A neurologist or general practitioner is not able to move forward in the EHR if the episode is not assigned a diagnosis that is automatically coded. Canadian researchers have applied a similar approach for identifying Parkinson's disease and dementia with good results $[13,35]$.

We have applied a binary classification that simplifies the heterogeneous way in which doctors describe NPS in the EHR. Moreover, we have consciously avoided including sleep disturbances within the scope of the research due to the bidirectional relationship between sleep disturbances and dementia [5]. Given that it is unclear whether dementia is a cause or consequence of sleep disturbance, we believe that the interpretation of predictive models based on the use of hypnotics would be very difficult, and hence, for the time being, have focused on psychotic and mood disorders.

\section{Conclusions}

More than half of the sample of dementia patients had NPS as identified by the presence of key terms in the electronic health record. Although NPS are not coded in the diagnosis registry, they are treated with antipsychotics and antidepressants, which allows developing valid predictive models by joining machine learning tools and real-world data. Given their good performance, the predictive models can be used to estimate prevalence of NPS in population databases.

\section{Declarations}

\section{Ethical Approval and Consent to participate}

The authors assert that all procedures contributing to this work comply with the ethical standards of the relevant national and institutional committees on human experimentation and with the Helsinki Declaration of 1975, as revised in 2008. All procedures involving human subjects/patients were approved by the Clinical Research Ethics Committee of the Basque Country (PI2018143).

\section{Consent for publication}

Each of the authors has substantially contributed to conducting the underlying research and agrees with the contents of the manuscript. 
Availability of data and materials

The dataset used and analyzed during the current study is available from the corresponding author on reasonable request.

\section{Competing interests}

The authors have no conflicts of interest to declare.

\section{Funding}

The study was funded by two grants from the Basque Foundation for Health Innovation and Research (BIOEF) (grant number BIOD17/ND/015) and Gipuzkoa Regional government (Adinberri program). The funding sources had no involvement in study design in the collection, analysis and interpretation of data, in the writing of the report; and in the decision to submit the article.

\section{Authors' contributions}

JM and AA (MU) conceived and designed the research. OI, AG, IL and AA (Osakidetza) obtained the data, and interpreted the data. $A A(M U), C C$ and EE designed the machine learning methods, performed the analyses and interpreted the data. AG performed the discrimination and calibration assessment. Al and MT designed the research, interpreted the data, and critically revised the manuscript. AA (MU) and JM drafted the manuscript and approved the final manuscript. AA (Osakidetza), OI, IL, AG, CC and EE revised the manuscript for important intellectual content and approved the final manuscript.

\section{Acknowledgements}

We would like to acknowledge the help of Ideas Need Communicating Language Services in improving the use of English in the manuscript.

\section{Authors' information}

The group of authors is made up of epidemiologists, clinicians, and computer engineers with complementary profiles, which has allowed machine learning techniques to be applied to real-world data.

\section{References}

1. Katona C, Livingston G, Cooper C, Ames D, Brodaty H, Chiu E. International Psychogeriatric Association consensus statement on defining and measuring treatment benefits in dementia. Int Psychogeriatr. 2007;19:345-54.

2. Gilhooly KJ, Gilhooly MLM, Sullivan MP, McIntyre A, Wilson L, Harding E, et al. A meta-review of stress, coping and interventions in dementia and dementia caregiving. BMC Geriatr. 2016;16:106.

3. Cummings J, Lee G, Ritter A, Sabbagh M, Zhong K. Alzheimer's disease drug development pipeline: 2019. Alzheimers Dement (N Y). 2019;5:272-93. 
4. Mar J, Arrospide A, Soto-Gordoa M, Iruin Á, Tainta M, Gabilondo A, et al. Dementia-related neuropsychiatric symptoms: inequalities in pharmacological treatment and institutionalization. Neuropsychiatr Dis Treat. 2019;15:2027-34.

5. Lanctôt KL, Amatniek J, Ancoli-Israel S, Arnold SE, Ballard C, Cohen-Mansfield J, et al.

Neuropsychiatric signs and symptoms of Alzheimer's disease: New treatment paradigms. Alzheimers Dement (N Y). 2017;3:440-9.

6. Halpern R, Seare J, Tong J, Hartry A, Olaoye A, Aigbogun MS. Using electronic health records to estimate the prevalence of agitation in Alzheimer disease/dementia. Int J Geriatr Psychiatry. 2019;34:420-31.

7. Stocks SJ, Kontopantelis E, Webb RT, Avery AJ, Burns A, Ashcroft DM. Antipsychotic Prescribing to Patients Diagnosed with Dementia Without a Diagnosis of Psychosis in the Context of National Guidance and Drug Safety Warnings: Longitudinal Study in UK General Practice. Drug Saf. 2017;40:679-92.

8. Ballard C, Gauthier S, Corbett A, Brayne C, Aarsland D, Jones E. Alzheimer's disease. Lancet. 2011;377:1019-31.

9. Brayne C. The elephant in the room - healthy brains in later life, epidemiology and public health. Nat Rev Neurosci. 2007;8:233-9.

10. Cummings JL, Mega M, Gray K, Rosenberg-Thompson S, Carusi DA, Gornbein J. The Neuropsychiatric Inventory: comprehensive assessment of psychopathology in dementia. Neurology. 1994;44:2308-14.

11. Cerejeira J, Lagarto L, Mukaetova-Ladinska EB. Behavioral and psychological symptoms of dementia. Front Neurol. 2012;3:73.

12. Mar J, Arrospide A, Soto-Gordoa M, Machón M, Iruin Á, Martinez-Lage P, et al. Validity of a computerized population registry of dementia based on clinical databases. Neurologia. 2018;

13. Jaakkimainen RL, Bronskill SE, Tierney MC, Herrmann N, Green D, Young J, et al. Identification of Physician-Diagnosed Alzheimer's Disease and Related Dementias in Population-Based Administrative Data: A Validation Study Using Family Physicians' Electronic Medical Records. J Alzheimers Dis. 2016;54:337-49.

14. Olfson M, King M, Schoenbaum M. Antipsychotic treatment of adults in the United States. J Clin Psychiatry. 2015;76:1346-53.

15. Anderson G, Oderkirk J, editors. Dementia Research and Care: Can Big Data Help? Paris: OECD Publishing; 2015.

16. Obermeyer Z, Emanuel EJ. Predicting the Future - Big Data, Machine Learning, and Clinical Medicine. N Engl J Med. 2016;375:1216-9.

17. Dimopoulos AC, Nikolaidou M, Caballero FF, Engchuan W, Sanchez-Niubo A, Arndt H, et al. Machine learning methodologies versus cardiovascular risk scores, in predicting disease risk. BMC Med Res Methodol. 2018;18:179. 
18. Moscoso A, Silva-Rodríguez J, Aldrey JM, Cortés J, Fernández-Ferreiro A, Gómez-Lado N, et al. Prediction of Alzheimer's disease dementia with MRI beyond the short-term: Implications for the design of predictive models. Neuroimage Clin. 2019;23:101837.

19. Doupe P, Faghmous J, Basu S. Machine Learning for Health Services Researchers. Value Health. 2019;22:808-15.

20. Fabris F, Magalhães JP de, Freitas AA. A review of supervised machine learning applied to ageing research. Biogerontology. 2017;18:171-88.

21. Breiman L. Random forests. Machine learning. 2001;45:5-32.

22. Biau G. Analysis of a Random Forests Model. Journal of Machine Learning Research. 2012;13:1063-95.

23. Landis JR, Koch GG. The measurement of observer agreement for categorical data. Biometrics. 1977;33:159-74.

24. Collins GS, Reitsma JB, Altman DG, Moons KGM. Transparent Reporting of a multivariable prediction model for Individual Prognosis or Diagnosis (TRIPOD): the TRIPOD statement. Ann Intern Med. 2015;162:55-63.

25. Steyerberg EW, Pencina MJ, Lingsma HF, Kattan MW, Vickers AJ, Van Calster B. Assessing the incremental value of diagnostic and prognostic markers: a review and illustration. Eur $\mathrm{J}$ Clin Invest. 2012;42:216-28.

26. Steyerberg EW, Van Calster B, Pencina MJ. [Performance measures for prediction models and markers: evaluation of predictions and classifications]. Rev Esp Cardiol. 2011;64:788-94.

27. David W. Hosmer Jr., Stanley Lemeshow, Rodney X. Sturdivant. Applied Logistic Regression. 3rd Edition. Hoboken, NJ, USA: John Wiley \& Sons, Inc; 2013.

28. Ponjoan A, Garre-Olmo J, Blanch J, Fages E, Alves-Cabratosa L, Martí-Lluch R, et al. Epidemiology of dementia: prevalence and incidence estimates using validated electronic health records from primary care. Clin Epidemiol. 2019;11:217-28.

29. Cummings J, Mintzer J, Brodaty H, Sano M, Banerjee S, Devanand DP, et al. Agitation in cognitive disorders: International Psychogeriatric Association provisional consensus clinical and research definition. Int Psychogeriatr. 2015;27:7-17.

30. Citrome L. Activating and Sedating Adverse Effects of Second-Generation Antipsychotics in the Treatment of Schizophrenia and Major Depressive Disorder: Absolute Risk Increase and Number Needed to Harm. J Clin Psychopharmacol. 2017;37:138-47.

31. Gallacher J, de Reydet de Vulpillieres F, Amzal B, Angehrn Z, Bexelius C, Bintener C, et al. Challenges for Optimizing Real-World Evidence in Alzheimer's Disease: The ROADMAP Project. J Alzheimers Dis. 2019;67:495-501.

32. Soto-Gordoa M, Arrospide A, Moreno-Izco F, Martínez-Lage P, Castilla I, Mar J. Projecting Burden of Dementia in Spain, 2010-2050: Impact of Modifying Risk Factors. J Alzheimers Dis. 2015;48:721-30. 
33. Brayne C, Davis D. Making Alzheimer's and dementia research fit for populations. Lancet. 2012;380:1441-3.

34. Zhu CW, Ornstein KA, Cosentino S, Gu Y, Andrews H, Stern Y. Misidentification of Dementia in Medicare Claims and Related Costs. J Am Geriatr Soc. 2019;67:269-76.

35. Butt DA, Tu K, Young J, Green D, Wang M, Ivers N, et al. A validation study of administrative data algorithms to identify patients with Parkinsonism with prevalence and incidence trends. Neuroepidemiology. 2014;43:28-37.

\section{Figures}

\section{a) Psychotic symptoms}

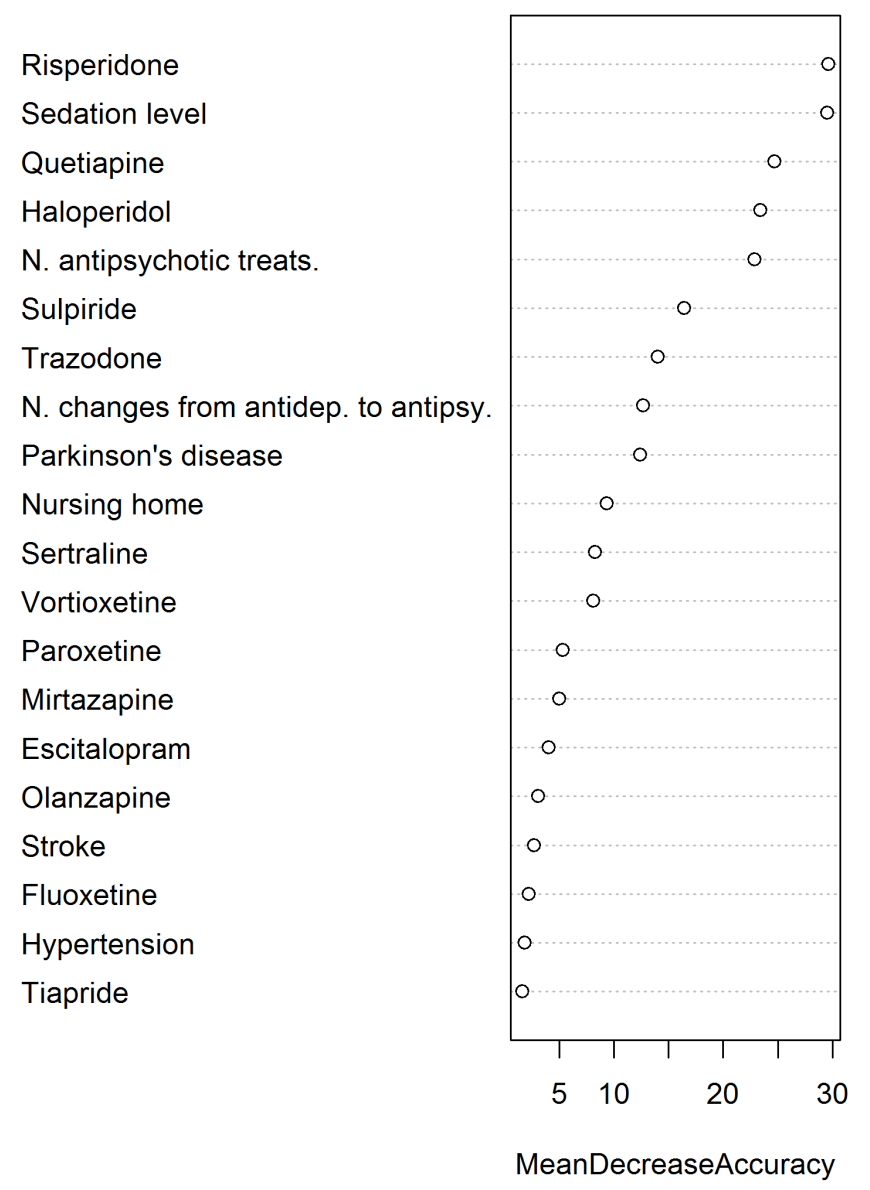

b) Depressive symptoms

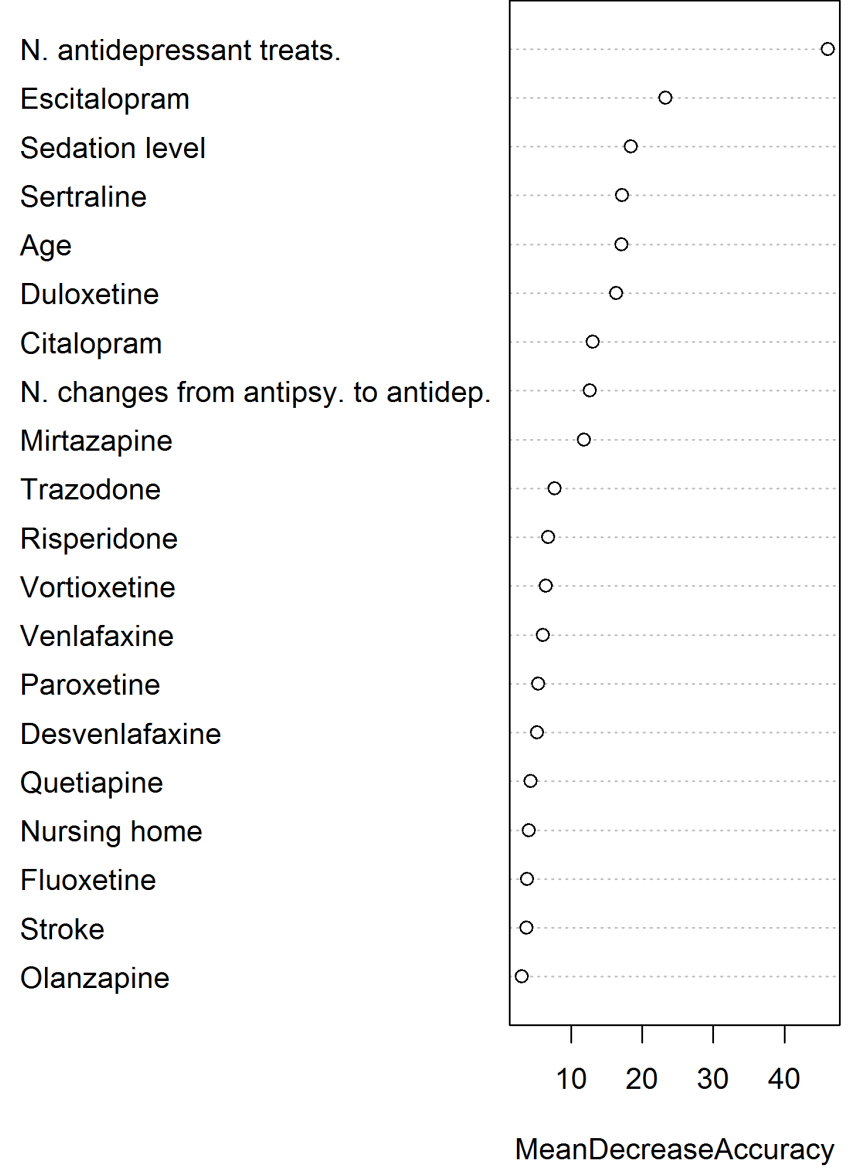

\section{Figure 1}

Importance of variables in selected models predicting psychotic and depressive symptoms. 


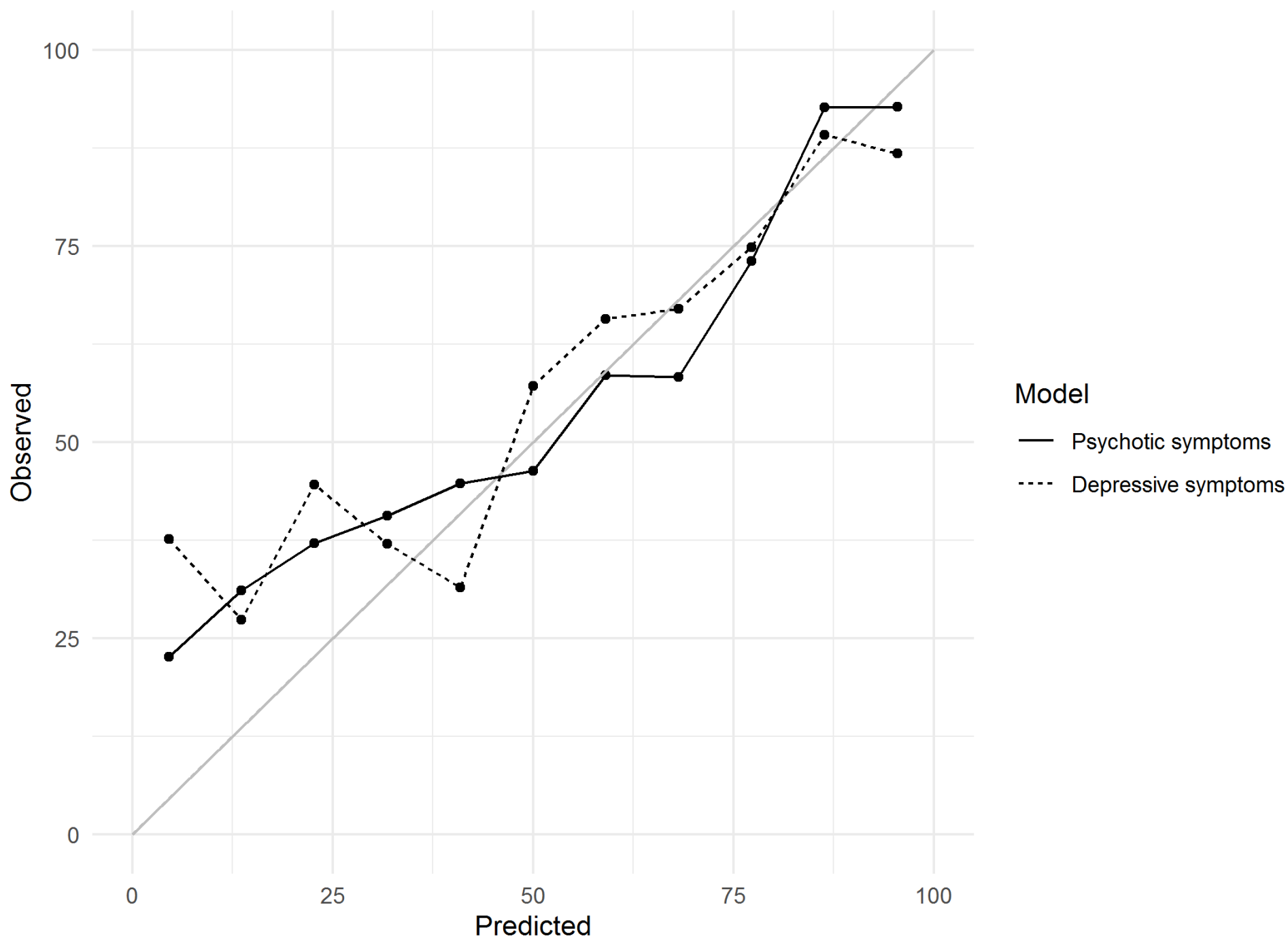

Figure 2

Calibration plot for selected models predicting psychotic and depressive symptoms in the validation sample. AUC: Area under the curve 


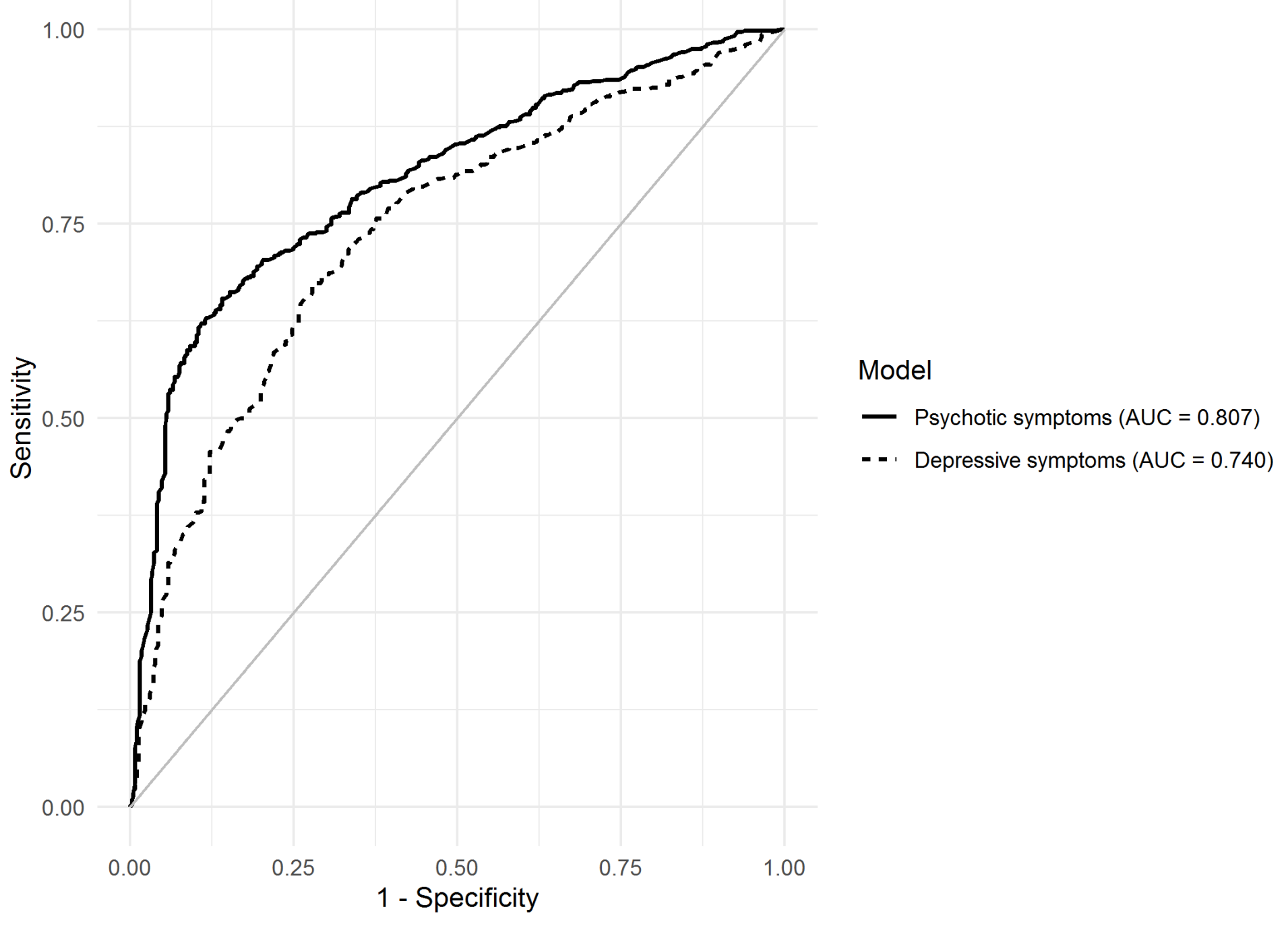

Figure 3

Area under the curve for selected models predicting psychotic and depressive symptoms in the validation sample. AUC: Area under the curve

\section{Supplementary Files}

This is a list of supplementary files associated with this preprint. Click to download.

- SupplemantarymaterialNPSpredictivemodelsvalidationART.docx 